\title{
Dynamic Conditions for a Three-level LLC Converter with a Phase-Pulse Control
}

\author{
K. V. Bykov ${ }^{1}, N . M$. Lazareva $^{2,1}$, and V.M. Yarov ${ }^{2,1}$ \\ ${ }^{1}$ EKRA Ltd, Cheboksary, Russia \\ ${ }^{2}$ The Chuvash State University, Cheboksary, Russia
}

\begin{abstract}
Usually, parametric synthesis of controllers for a closed control system is carried out for nominal conditions, and then the source performance for other load resistance values is estimated. As a result, the control system may not always provide the sufficient mode stabilization with a changing load resistance value. The paper suggests an alternative version. It deals with estimation of dynamic transient responses for the required mode parameter in an open-circuit system as well as with determination of transfer functions and the controller parameters for the most complicated version of transient response curves. The paper presents the results of simulation modelling of dynamic operating conditions for LLC converter using Simulink Matlab as well as load characteristics for three versions of a closed control system.
\end{abstract}

\section{Introduction}

Today, a variable frequency drive (VFD) is usually offered for LLC converters in the literature [1-6]. As a result, the change over time in the frequency rate makes it impossible to develop a power transformer optimally as well as makes it difficult to filter higher harmonics due to the changing spectrum. Also, phase-pulse control at constant frequency is available in a full-bridge LLC converter [7-9]. The advantages of such control may be as follows:

- Zero voltage switching (ZVS) mode could be achieved at wider load range;

- Low overvoltages at the output rectifier diodes may allow excluding a choke from the output filter;

- Much simpler arrangement for current protection in comparison to LLC variable frequency converter.

\section{Methods}

The use of the half-bridge (HB) three-level (TL) LLC converter with phase-pulse control (Figure 1) may allow gaining an additional advantage while using an equal number of transistors. The advantage is that $600 \mathrm{~V}$ transistors could be used for three-phase power supply while $1200 \mathrm{~V}$ transistors would be required for a fullbridge (FB) version [10-13].

The output voltage may be stabilized by introducing compensatory feedbacks. It would be necessary to determine the input/output and control/output transfer functions for determining the parameters of feedback circuits at given static and dynamic characteristics. They could be derived by solving differential equations or as a result of measuring the frequency response, which may require quite a lot of effort. Alternatively, a transfer function may be based on the acceleration curve considered to be a transient characteristic [14] which could be measured by Simulink Matlab simulation (Figure 2).

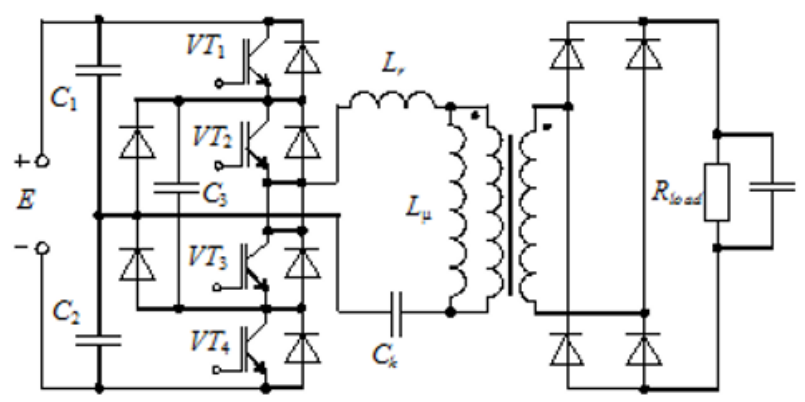

Fig. 1. HB TL LLC converter.

\section{Results}

Time diagrams of currents and voltages for the steadystate operating mode of TL LLC converter (Figure 1) obtained as a result of Simulink Matlab modeling are shown in Figure 3.

\footnotetext{
* Corresponding author: lana21lana21@mail.ru
} 


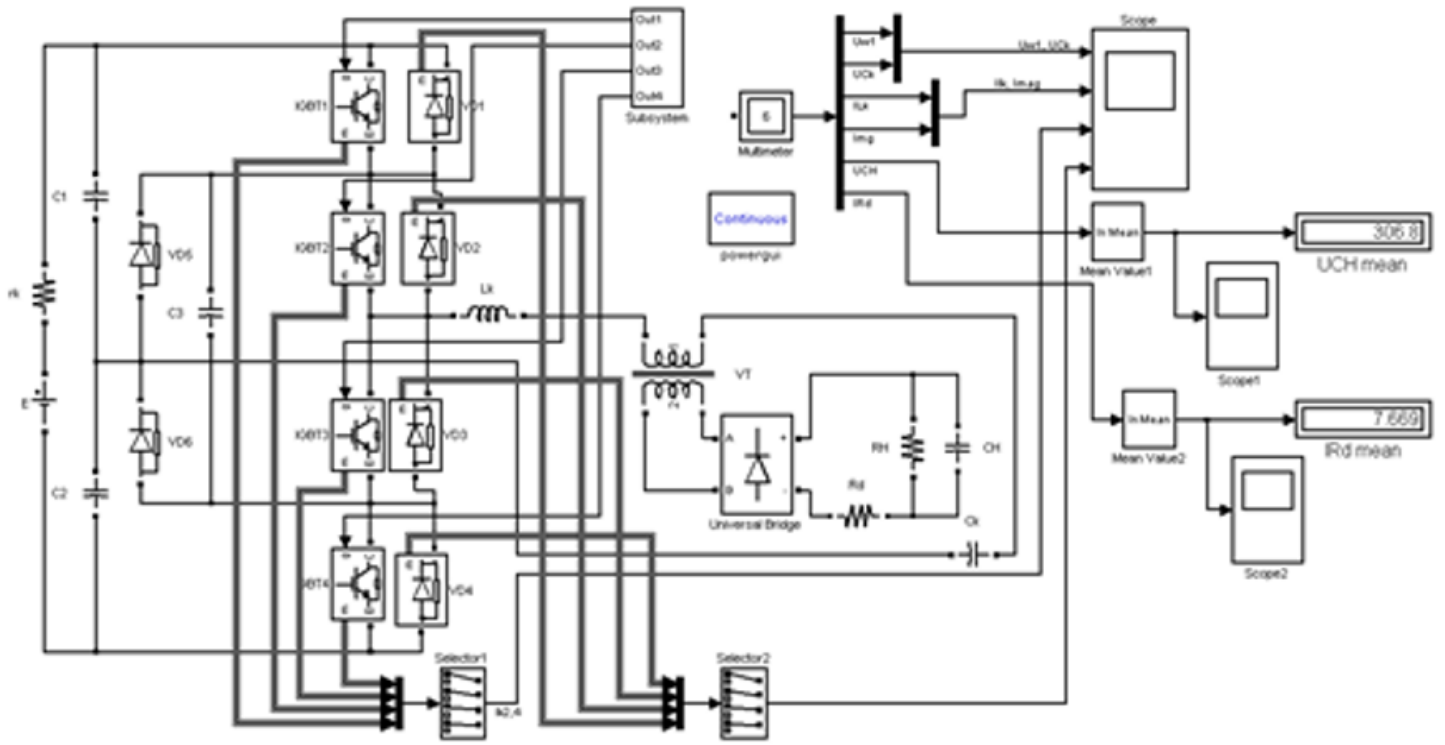

Fig. 2. Simulink model of TL LLC converter.

To measure the converter transient response after the transformer has reached the steady-state operation, the control system abruptly changes $\gamma$ pulse duty ratio of the transistor current. So, the normalized transition process of changes in current or load voltage would represent the transient response. The transient response behavior may depend on load resistance significantly so that the degree of its oscillation would vary with changes in $R_{\text {load }}$ (Figure 4).

It may be assumed on the basis of the transient response that the converter could be represented by an oscillating link with the transfer function as follows:

$$
W(p)=\frac{K}{T^{2} p^{2}+2 \xi T p+1} .
$$

Here, time constant $T$ and index of oscillation $\xi$ may be determined by the following formulas [14]:

$$
\begin{aligned}
& T=1 / \sqrt{\left(\frac{2 \pi}{T_{1}}\right)^{2}+\left[\frac{\ln \left(A_{1} / A_{2}\right)}{T_{1}}\right]^{2}} ; \\
& \xi=\frac{T}{T_{1}} \ln \left(A_{1} / A_{2}\right) .
\end{aligned}
$$
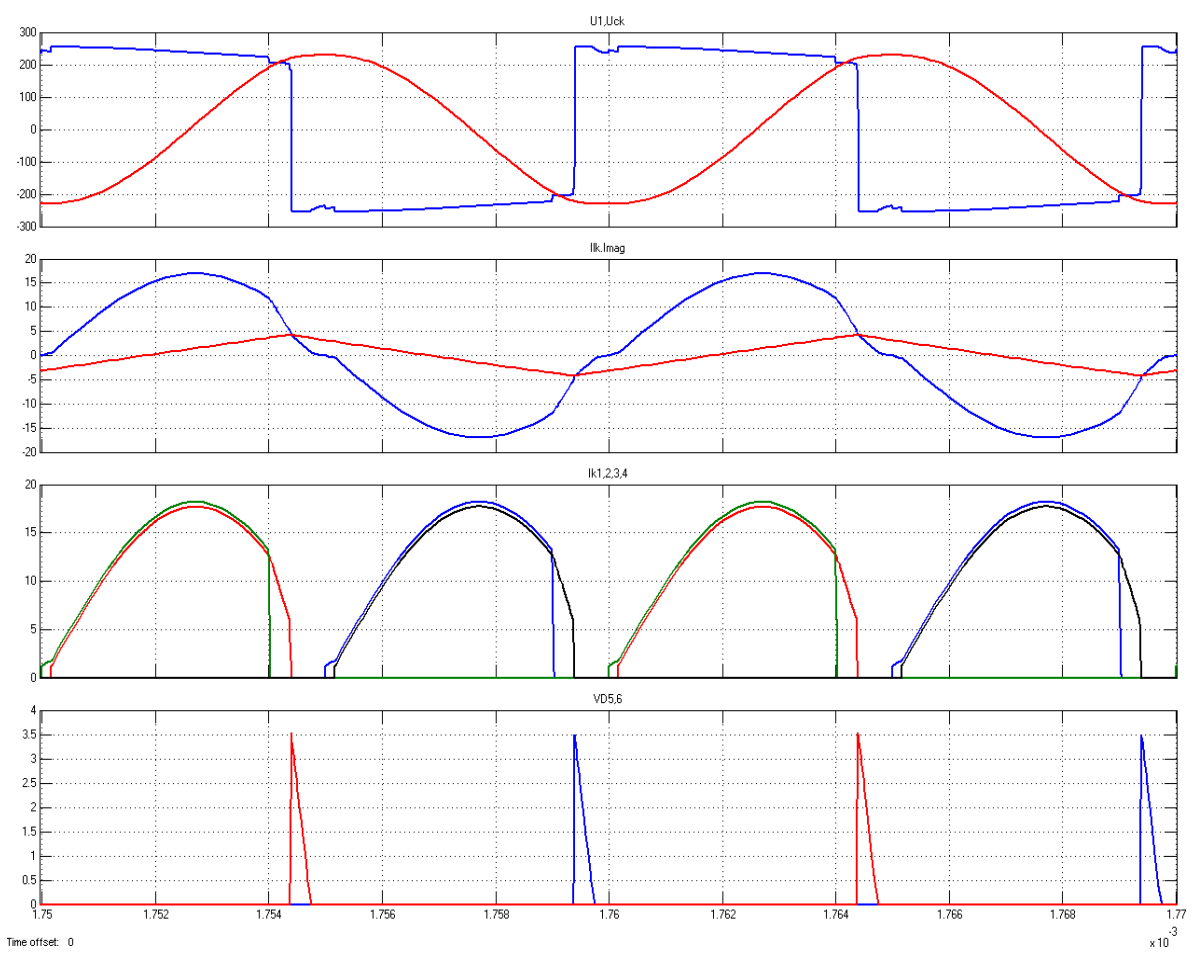

Fig. 3. Time diagrams for LLC converter operating mode. 

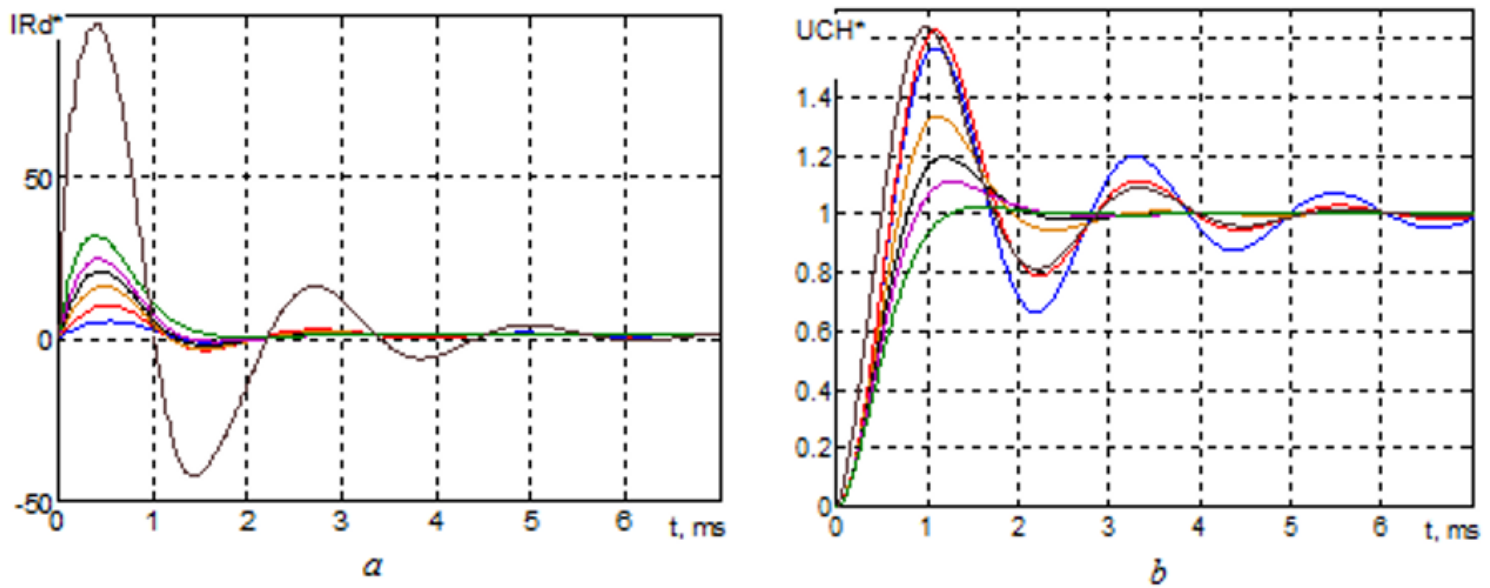

Fig. 4. Transient response curves of the rectified current (a) and load voltage (b) of the converter with an open-circuit control system while changing $R_{\text {load }}$ from 10 to $300 \mathrm{Ohm}$.

Here, parameters $T_{1}, A_{1}$ and $A_{2}$ may be determined by the transient response, while $K$ is the converter transfer ratio.

Basing on the transient response curve having the highest degree of oscillation, it may be obtained for the converter transfer function in terms of load voltage that $T=43 \cdot 10^{-6} \mathrm{~s}$ and $\xi=0.185$.

It could be revealed while determining the converter transfer function in terms of load voltage that one link (1) may be insufficient, so the introduction of an optimum lead network is required. Its temperature constant could be also determined by the current transient response as a derivative value in a neighborhood of $t=0 \mathrm{~s}$. Alternatively, a logarithmic amplitude-phase frequency characteristic of the converter could be constructed on the basis of the transient response curve [14], and then the frequency response of the oscillating link with characteristics derived from equations (2) should be subtracted from it. As a result, frequency response of the lead network would be obtained, thus allowing determining its time constant simply. Thus, LLC converter in terms of the rectified current could be represented by the link $W(p)=\frac{K(\tau p+1)}{T^{2} p^{2}+2 \xi T p+1}, \quad$ where $\quad \tau=2.37 \cdot 10^{-4} \mathrm{~s} ;$ $T=35 \cdot 10^{-6} \mathrm{~s} ; \xi=0.346$.

Having the converter model as a transfer function, characteristics of $P I$-controller of electrical mode could be determined, for example, by the root method $[14,15]$. Thus, transfer ratio of the proportional part of the controller could be written as follows:

$$
K_{p}=\frac{1}{K_{0}}\left(\beta^{2}+3 \alpha^{2}-a_{0}\right),
$$

while integral coefficient could look like the following:

$$
K_{i}=\frac{\alpha}{K_{0}}\left(\beta^{2}+\alpha^{2}\right) .
$$

Here, $\alpha \pm j \beta$ are roots of a characteristic equation for the transfer function of a closed-circuit system which could be determined on the basis of Vieta theorem; $K_{0}=K / T^{2} ; a_{0}=1 / T^{2}$.

Transient processes of load voltage variation in a closed-circuit system along with parameters of $P I$ controller calculated by equations (3) and (4) for different values of load resistance are shown in Figure 5. The nature of all transients is aperiodic, so modelling the converter on the basis of load voltage by oscillating link as well as determining the parameters of $P I$-controller on the basis of transient response having the highest degree of oscillation may be justified. Control time may be reduced by correcting the parameters and structure of the controller.

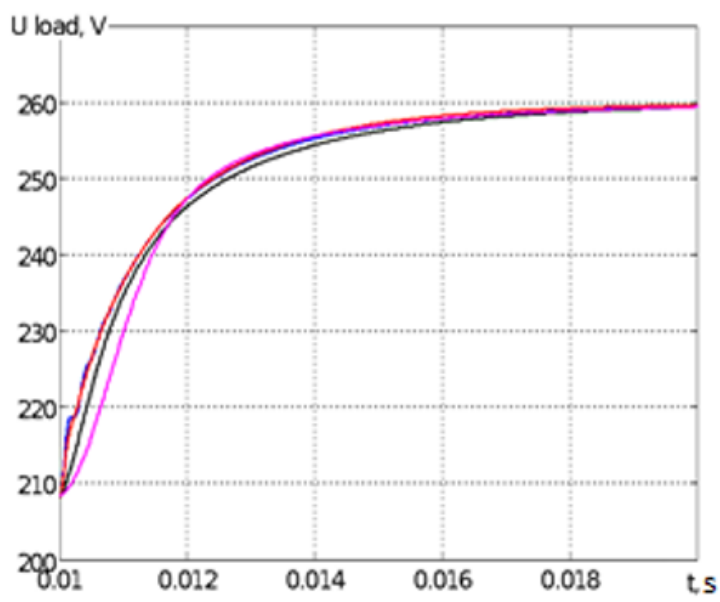

Fig. 5. Transient processes of load voltage variation in the converter with a voltage circuit while changing $R_{\text {load }}$ from 10 to $300 \mathrm{Ohm}$.

Similar results have been also obtained for the rectified current circuit. Load characteristics $U_{\text {load }}=f\left(I_{R_{d}}\right)$ confirming the efficiency of the load voltage regulating circuit and the rectified current circuit which parameters have been calculated on the basis of the transient response curves are shown in Figure 6. 


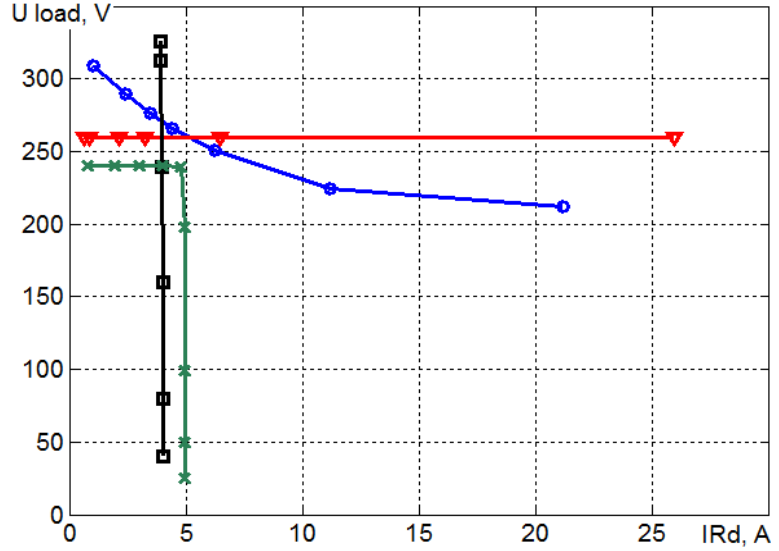

Fig. 6. Load characteristics: -o- is an open-loop control system; - $\mathbf{\nabla}$ - is a system closed by load voltage; $-\mathbf{m}-$ is a system closed by rectified current; - $-x$ - is a slave control system.

If the transient response curve of load voltage of the converter with the control system closed by rectified current is determined, then it could be possible to calculate the parameters of $P I$-controller for a slave control system.

Load characteristic of the converter with a twocircuit control system is shown as a jog line in Figure 6, where load voltage is stabilized up to current values not exceeding $5 \mathrm{~A}$ while at strong currents the rectified current is maintained unchanged.

\section{Conclusions}

The voltage or current transfer functions of the LLC converter could be more easily determined by the transient response obtained by applying step disturbance after the transformer has reached the steady-state operating mode, as compared to the frequency response method. With the transformer transfer function known, parameters of the electrical mode controller could be calculated by the root method.

\section{References}

[1] L. Malesani, P. Mattavelli, L. Rossetto, others Electronic Welder with High-Frequency Resonant Inverter. IEEE Transactions on Industry Applications, vol. 31(2), 1995 March/April (1995)

[2] Yu. Novikov, M. Solomatin, Development of a Half-Bridge Resonance Converter on the Basis of IRS2795. Electronic Components, 3, 103-111, (in Russ) (2011)

[3] Fairchild Semiconductor Corporation Application Note AN-4151: Half Bridge LLC Resonant Converter Design Using FSFR-series Fairchild Power Switch Rev1.0.0, 10/09/2007

[4] B. Yang, P. Xu, F.C. Lee, Range Winding for Wide Input Range Front End DC/DC Converter. Proc. IEEE APEC, 476-479 (2001)

[5] V.I. Meleshin, D.A. Ovchinnikov, Controlling of Power Transistor Transformers. Moscow, Technosphere Publ., 576, (in Russ) (2011)
[6] F. Conoles, Novel DC/DC Converters for High-Power Distributed Power Systems. Dissertation submitted to the Faculty of the Virginia Polytechnic Institute and State University in partial fulfillment of the requirements for the degree of Doctor of Philosophy in Electrical Engineering. Virginia Polytechnic Inst. and State Univ (2003)

[7] B. Yang, F.C. Lee, A.J. Zhang, G. Huang, LLC Resonant Converter for Front End DC/DC Conversion. In: Seventeenth Annual IEEE APEC, 2, 1108-12 (2002)

[8] B. Yang, F.C. Lee, M. Concannon, Over Current Protection Methods for LLC Resonant Converter. Proc. IEEE APEC. 2, 605-609 (2003)

[9] M. Zhang, S. Hu, Phase Shifted Full Bridge LLC Resonant Converter. ASTEC China Design Engineering, Emerson Network Energy Corp. Shenzhen, 518133, Guangdong Province, P.R. China (2008)

[10] C. Adragna, S. De Simone, C. Spini, A Design Methodology for LLC Resonant Converters Based on Inspection of Resonant Tank Currents. In: Twenty-Third Annual IEEE APEC. 1361-67 Austin, TX, USA.

[11] Designing an LLC Resonant Half Bridge Power Converter. Reproduced from 2010 Texas Instruments Power Supply Design Seminar SEM 1900, Topic 3 TI Literature Number: SLUP263.

[12] L. Bing, L. Wenduo, Y. Liang, C.L. Fred, D. Jacobus, V. Wyk Optimal Design Methodology for LLC Resonant Converter. APEC, 533-538 (2006)

[13] G. Yilei, L. Zhengyu, H. Lijun, Q. Zhaoming, H. Guisong, Three-level LLC Series Resonant DC/DC Converter. IEEE Transactions on Power Electronics, vol. 20, July 2005, 781-789 (2005)

[14] N. Shavarin, V. Yarov, N. Lazareva, TwoPhase Boost Converter as a Part of the Automatic Control System. Power Electronics, 3, 40-46, (in Russ) (2015)

[15] N. Shavarin, V. Yarov, N. Lazareva, Dynamic Calculation of the Two-Phase Boost Converter. Power Electronics, 4, 48-56, (in Russ) (2015) 